\title{
ENERGY STORAGE IN SMART GRIDS
}

\author{
Jiří Polívka
}

\section{ABSTRACT}

This paper deals with one part of so called SMART GRIDS systems, which is storage of electrical and thermal energy, preferably in small scale applications, such as family houses, apartment houses or small commercial buildings. Distributed energy storage systems in combination with advanced power electronics will play a great technical role and it will have a huge impact on the electrical supply systems in the future and it should lead to many economical benefits.

\section{KEYWORDS}

Energy storage, smart grids, microgrids

\section{INTRODUCTION}

Power system in the Czech Republic faces significant changes due to increasing demand for reliable electric power generation, wider public awareness of environmentally friendly energy sources, along with antipathy to the traditional sources of installations to the electricity grid. The aging of transmission lines and production facilities has also considerable effect. The annual growth of $1.5 \%$ of electricity demand is predicted from 2010 in compliance with the baseline scenario of energy consumption. Alternative scenarios outlined in Fig. 1, are based on assumptions, such as increased demand for electricity in developing countries, rapid technological advances, the threat of climate change, etc.

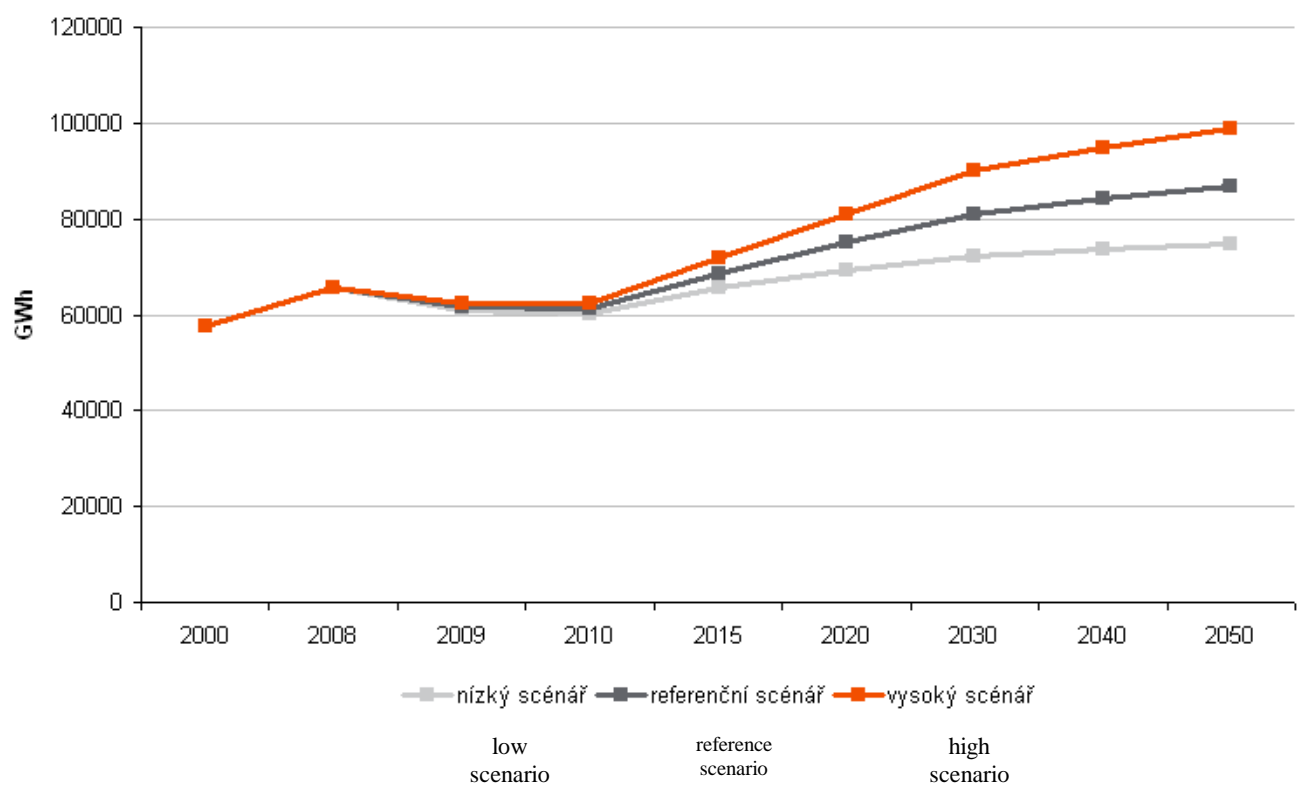

Fig. 1 - Electricity consumption forecast in the Czech Republic [3] 


\section{CUSTOMER DRIVEN MICROGRIDS}

The energy storage in connection with MICROGRIDS becomes almost indispensable when energy production is happening at a time. Besides the basic function of the energy storage in the re-release of surplus energy, this system is used in combination with appropriate power electronics (PE) as well as frequency and voltage regulator, improving the reliability of demanded power, power factor compensator and a compensator of instantaneous power fluctuations network.

As shown in Fig. 2. energy storage can be accomplished in several ways. Fig. 2 (a) shows separate module connected to microgrid via two-way interface PE. The modules in Fig. 2 (b) and (c) uses for its functions an energy source. With proper management, these two systems can work almost identically. In Fig. 2 (c) source of energy and energy storage are connected, mostly by DC jumper. If volatile source of renewable energy (solar, wind) has been considered, the accumulation module provides the ability to balance power and this system delivers continuous flow of electrical energy.
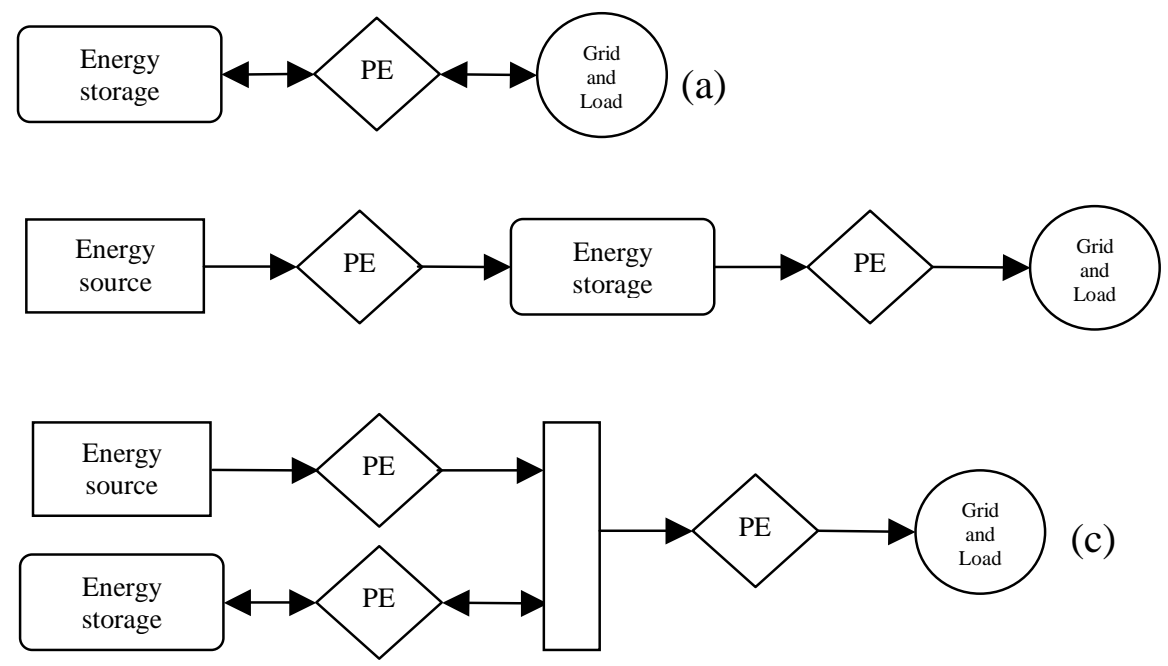

Fig. 2 - The schematic arrangement of the different types of energy storage in microgrids [2]

\section{CONCLUSIONS}

The appropriate combination of energy storage and thermal energy storage with renewable resources and SmartGrids technologies in the residential sector, mainly in family homes, it can significantly reduce energy consumption and thus significant funds savings expended to cover these energies.

\section{REFERENCES}

[1] Ter-Gazarian, A.: Energy storage for power systems, IEE Energy, 1994

[2] Suryanarayanan, S.; Mancilla-David, F.: Achieving the Smart Grid Through CustomerDriven Microgrids Supported by Energy Storage, IEEE International Conference on Industrial Technology 2010

[3] www.cez.cz

\section{ACKNOWLEDGMENT}

This work was supported and granted by project no. SGS 2010-018. 


\section{Author:}

Ing. Jiří Polívka

University of West Bohemia

Department of Electrical Power Engineering and Environmental Engineering

Univerzitní 8, 30614 Plzeň, Czech Republic

E-mail: jpolivka@kee.zcu.cz

Tel: +420377634374 